\title{
BENTUK TARI MANOE PUCOK PADA MASYARAKAT BLANGPIDIE ACEH BARAT DAYA
}

\author{
NOVINTA SARI \\ Prodi PendidikanSeniTari
}

\begin{abstract}
Abstrac
Based on research that has been done, the history of dance ManoePucok derived from malelang-madion story taken from the story of dance Pho. Where they were executed as a result of slander prime minister, where the grief of a mother loses her daughter forever. Based on this story, dance ManoePucok no longer tells of the sadness of a mother on her daughter died as a result of execution. But this ManoePucok dance tell the sadness of a mother, who lost her daughter to remove the bachelor married to happiness. This form of dance is twofold, form the internal structure and external structure forms. We can see the internal form of grief a mother take off her daughter into a new life, through internal forms of dance ManoePucok, the mother expressed her sorrow to remove the bachelor. External shape seen from the motion that the entrance motion, shalawat motion, Trontajakmanoe motion, taking water motion, flush head motion, TrontajakManoe motion, the motion of hair shampoo and body motion flush. There are six forms the floor pattern, the pattern of two lines up, a triangle pattern, the pattern of $v$, the pattern of the two row, and a half-circle pattern. Accompaniment, fashion, and makeup, which have meaning ManoePucok dance performances. ManoePucok dance is performed before the consent granted do.
\end{abstract}

Keywords : Forms, dance ManoePucokBlangpidie community 


\section{PENDAHULUAN}

Aceh merupakan daerah yang subur dan kaya akan hasil alamnya, antara lain berupa padi, cengkeh, lada, pala, kelapa, kopi, dan lain-lain. Oleh karena itu mata pencaharian pokok masyarakat Aceh adalah bertani di sawah dan ladang. Adapun masyarakat yang bermukim di sepanjang pantai dengan mata pencaharian sebagai nelayan. Berbagai jenis pencaharian masyarakat Aceh, namun sebagian besar masyarakatnya adalah sebagai petani padi. Mata pencaharian marupakan suatu kebiasaan pada masyarakat tertentu, dan merupakan salah satu unsur kebudayaan. Dalam hal ini kebudayaan bersifat abstrak. Kebudayaan sebagai hasil karya rasa dan cipta, bermakna kebudayaan bersifat kongkrit, ada perwujudannya dalam kehidupan masyarakat berupa perilaku dan benda-benda yang bersifat nyata. Misalnya pola perilaku (adatistiadat), bahasa peralatan hidup, organisasi social, religi, seni, dan lainlain yang semuanya ditunjukan untuk membantu manusia dalam melangsungkan hidup masyarakat dan keagamaan atau kepercayaan terhadap Tuhan Yang Maha Esa. Setiap daerah memiliki kebudayaan yang beraneka ragam, salah satunya yaitu provinsi Aceh. Adapun unsur kebudayaan itu dituangkan dalam bentuk keseian yaitu tari.

Tari Manoe Pucok merupakan kisah yang di ambil dari cerita tentang legenda Malelang-Madion. MalelangMadionadalah kisah kehidupan sepasang kekasih yang saling mencintai, namun kisah cinta meraka harus berakhir di usia muda, karena hasutan perdana menteri yang pernah di tolak pinangannya oleh Madion, mereka dituduh telah menodai kesucian kerajaan dengan berbuat zina sehingga dijatuhkan hukuman mati oleh pihak kerajaan. Legenda MalelangMadion telah sangat lama berkembang dan mempengaruhi kehidupan masyarakat di pesisir Barat Daya Aceh, khususnya di Aceh Barat daya. Adanya perekembangan zaman di tengah-tengah masyarakat aceh Barat Daya, tari Pho tidak lagi di tarikan, karen adanya unsur meratap yang sangat di larang oleh agama islam, lambat laut masyarakat setempat pun menyebutkannya dengan tari Manoe Pucok.

Tari Manoe Pucok merupakan suatu tradisi di dalam ritual perkawinan di Aceh Barat daya yang ditarikan sebelum ijab kabul dilakukan. Tari Manoe Pucok merupakan pelengkap upacara perkawinan bagi masyarakat Blangpidie, dan tidak semua masyarakat Blangpidie melakukan acara Manoe Pucok, hanya beberapa masyarakat yang 
mempunyai rezeky lebih bisa melakukan upacara Manoe Pucok yang di dalamnya terdapat nasehat-nasehat orangtua kepada anaknya agar bisa menjalani kehidupan yang bahagia setelah menikah. Tarian ini di lakukan sehari sebelum menjelang acara peresmian di kediaman pengantin wanita. Tari Manoe Pucok adalah tarian yang memilki unusr-unsur tragedi Malelang-Madion dalam tarian Pho. Tradsi ini berubah bagian syair-syairnya dan gerak-geraknya, sehingga berbeda dari syair yang ada pada tari Pho yang asli, namun esensi meratap dan Tron tajak manoe tetep di pertahankan dalam syair tari Manoe Pucok.

Oleh karena itu, maka penulis tertarik untuk menjadikan Bentuk Tari Manoe Pucok Pada Masyarakat Blangpidie Aceh Barat Daya. Tujuan yang ingin di capai dalam penelitian ini adalah :

1. Mendeskripsikan sejarah tari Manoe Pucok pada masyarakat Blangpidie Aceh Barat Daya.

2. Mendeskripsikan bentuk tari Manoe Pucok pada masyarakat Blangpidie Aceh Barat Daya.

\section{Landasan Teori}

Untuk membahas Bentuk tari Manoe Pucok pada masyarakat Blangpidie Aceh Barat daya penulisan ini menggunakan beberapa teori yaitu teori bentuk dan makna.

\section{Lokasi dan Waktu Penelitian}

Sesuai dengan judul penelitian (Bentuk Tari Manoe Pucok pada Masyarakat Blangpidie Aceh Barat daya), maka penelitian ini dilakukan di Gampong Ujung Padang Kecamatan Susoh, Kabupaten Aceh Barat Daya. Waktu yang di perlukan dalam mengumpulkan data adalah dua bulan di mulai dari bulan desember 2015sampai akhir bulan maret 2016 .

\section{Populasi dan Sampel \\ Populasi}

Populasi dalam penelitian ini adalah tokoh-tokoh adat masyarakat Blangpidie Aceh Barat Daya atau seniman-seniman yang mengetahui bentuk tari Manoe Pucok.

\section{Sampel}

$$
\text { Adapun }
$$
yang menjadisampelpadapenelitianiniadala hsemua yang adapadapopulasiyaitutokohtokohadat, parasenimansenimandanmasyarakat yang terlibatdalamacaraManoePucokterseb ut. 
Olehsebabitupenelitianinidisebutjuga penelitianpopulasi

\section{Teknik Pengumpulan Data}

Teknik pengumpulan data yang di lakukan adalah sebagai berikut :

\section{Observasi}

\section{Teknik Analisis Data}

Untuk mengelola data penelitian maka seorang peneliti harus melakukan teknik analisis data, data analisis data harus dilakukan sejak sebelum mamasuki lapangan, selama di lapanagn, dan setelah selesai di lapangan. Penganalisis data di lakukan dengan cara

\section{ISI}

\section{Letak geografis Aceh Barat Daya}

Aceh Barat Daya merupakan pemekaran dari Kabupaten induk, yaitu Aceh Selatan, karena udah sepantasnya Aceh Barat Daya menjadi Kabupaten yang otonom karena segi pendapatan penduduk, dan segi geografis, Aceh Barat daya sudah saatnya berdiri sendiri untuk membentuk suatu Kabupaten yang otonom bukan semudah membalikan telapak tangan, butuh perjuangan dari sesepuh kita yang telah mengorbankan
2. Wawancara

3. Dokumentasi

4. Studi kepustakaan deskriptif kualitatif yaitu jenis penelitian yang memberi gambaran, uraian, keterangan, dan mencari fakta. Analisis deskriptif kualitatif merupakan metode penelitian yang dilakukan sesuai faktafakta sosial untuk mengkaji dan membahas mengenai Bentuk Tari Manoe Pucok Pada Masyarakat Blangpidie Aceh Barat Daya. daya dan upaya sehingga Aceh Barat Daya menjadi sebuah Kabupaten yang resmi dari segi hukum otonom, dan bukanlah merupakan akses dari reformasi pada tahun 1998 semata. Meskipun pemerintahan saat itu mempercepat pemekaran tersebut, namun wacana untuk pemekaran itu sendiri sudah berkembang sejak tahun 1960. Secara Geogarafis Kabupaten Aceh Barat daya terletak antara $3^{\circ} 05^{\prime}-$ $3^{\circ} 80^{\prime}$ Lintang Utara dan $96^{\circ} 23^{\prime} 02^{\prime \prime}$ $-\quad 97^{\circ} \quad 23 " \quad 03 ”$ 
BujurTimurdenganluaswilayah $2.334,01 \mathrm{Km}^{2}$.

\section{Upacara Pernikahan}

setiap daerah pasti mempunyai upacara pernikahan sendiri dengan aturan-aturan yang sudah turun menurun dari nenek moyang kita. Begitu juga dengan masyarakat Aceh yang mempunyai aturan-aturan dalam prosesi menuju pernikahan, di antaranya: $\mathrm{Cah}$ Rot (Menanya), Jak Meulakee (Meminang), Duek Pokat (Musyawarah keluarga perempuan), Ranup Kong Haba (Sirih Pertunangan), Jak Bak Tanda (Tunangan), Pajoh Bu Tuha (Membentuk Panitia Pernikahan), Bah Gaca (Berinai), Manoe Pucok (Mandi Pengantin), Akad Nikah, Walimah dan Antar Lintong.

\section{Struktur Eksternal (struktur luar)}

Gerakmerupakanbagian yang paling

pentingdalamsebuahtari.Didalamtari bukanlahgerak yang realistis, melainkangerak yang telahdiberibentukGerakekspresifdane stetis. Geraktariselalum melibatkanunsuranggotabadanmanus ia.Gerakdalamtariberfungsisebagai media untukmengkomunikasikanmaksudmaksudtertentudarikoreografer.Gera ktariManoePucokmerupakangerak yang menggambarkanbagaimanacaraibum emandikananaknya, bagaimanacaraibumembasuhbadanan aknyadan lain-lain. Sepertigeraksalam, geraktrontajakmanoe, gerakmengambil air, menyiramkepala, gerakmencucikepala (keramas) dangerakmenyiramtubuh.

\section{Pola lantai}

Dalam sebuah tarian pola lantai adalah salah satu bagian yang sangat berperan dalam sebuah tarian. Dalam tari Manoe Pucok ini memiliki bagian-bagian pola lantai yang cukup sederhana tetapi terlihat sangat indah, diantaranya pola dua baris, pola segitiga pola lingkaran, pola kerucut, pola dua banjar dan pola setengah lingkaran. Semua rangkaian bentuk pola lantai pada tari Manoe Pucok idientik dengan pola lingkaran, seperti di dalam cerita Malelang Madion, sang ibu dan para kerabat melingkari jenazah 
kedua anaknya tersebut. Dalam setiap pengantin pola akan membentuk pola lingkaran terlebih dahulu samapai akhir.

\section{Syair}

\begin{tabular}{|c|c|c|}
\hline No. & Syair & Arti \\
\hline 1. & $\begin{array}{l}\text { Dengan } \\
\text { bismillah lon } \\
\text { peuphon rawi } \\
\text { Lake bak Rabbi } \\
\text { beu sampurna } \\
\text { Dari awai phon } \\
\text { sampoe ngon } \\
\text { akhe } \\
\text { Beu meu sampe } \\
\text { peumanoe gata }\end{array}$ & $\begin{array}{l}\text { Dengan } \\
\text { bismillah } \\
\text { saya } \\
\text { Kita } \\
\text { meminta } \\
\text { kepada } \\
\text { tuhan untuk } \\
\text { sempurna } \\
\text { Dari pertama } \\
\text { sampai } \\
\text { selesai } \\
\text { Agar acara } \\
\text { mandi ini } \\
\text { baik untuk } \\
\text { mu }\end{array}$ \\
\hline 2. & $\begin{array}{l}\text { Tron tajak } \\
\text { manoe } \\
\text { Dara baro tron } \\
\text { tajak manoe } \\
\text { Oh lheuh manoe } \\
\text { lakee sunalein } \\
\text { Ija nyang laen } \\
\text { seunalen manoe }\end{array}$ & $\begin{array}{l}\text { Turun kita } \\
\text { mandi } \\
\text { Mempelai } \\
\text { puti turunlah } \\
\text { Kita pergi } \\
\text { mandi } \\
\text { Sesudah } \\
\text { mandi } \\
\text { Minta } \\
\text { salinan kain } \\
\text { yang lain } \\
\text { salinan } \\
\text { mandi }\end{array}$ \\
\hline
\end{tabular}

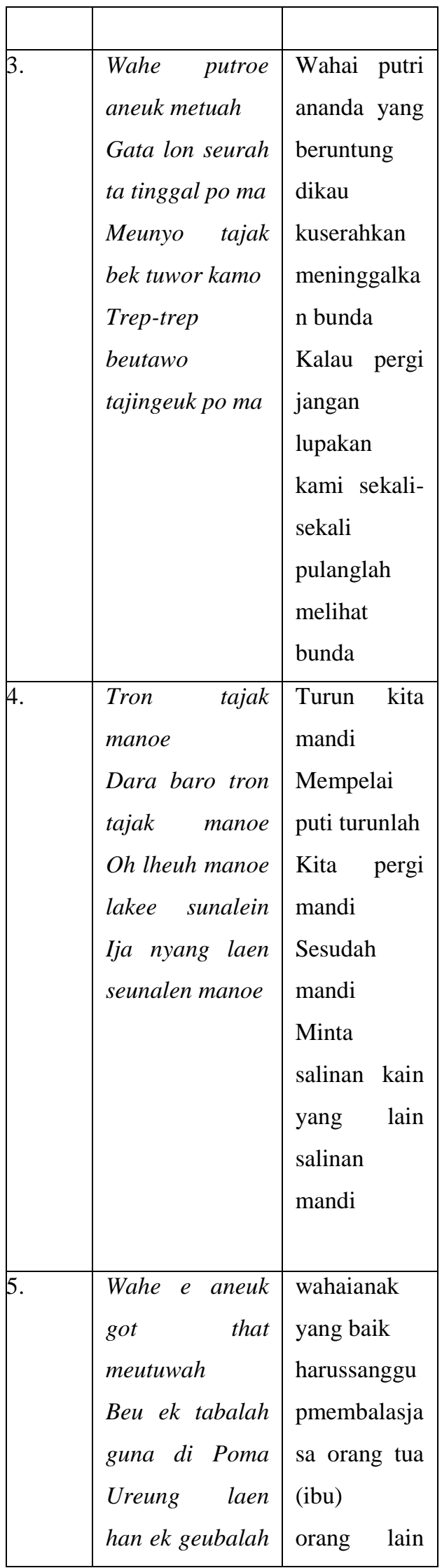




\begin{tabular}{|c|c|c|}
\hline & $\begin{array}{l}\text { Melainkan Allah } \\
\text { balah guna ma }\end{array}$ & $\begin{array}{l}\text { tidaksanggu } \\
\text { pmembalas } \\
\text { melainkanall } \\
\text { ah yang } \\
\text { membalas }\end{array}$ \\
\hline 7. & $\begin{array}{l}\text { Tron tajak } \\
\text { manoe } \\
\text { Dara baro tron } \\
\text { tajak manoe } \\
\text { Oh lheuh manoe } \\
\text { lakee sunalein } \\
\text { Ija nyang laen } \\
\text { seunalen manoe }\end{array}$ & $\begin{array}{l}\text { Turun kita } \\
\text { mandi } \\
\text { Mempelai } \\
\text { puti turunlah } \\
\text { Kita pergi } \\
\text { mandi } \\
\text { Sesudah } \\
\text { mandi } \\
\text { Minta } \\
\text { salinan kain } \\
\text { yang lain } \\
\text { salinan } \\
\text { mandi }\end{array}$ \\
\hline 8. & $\begin{array}{l}\text { Bak tanggai } 3 \\
\text { November thon } \\
88 \\
\text { Gata hai intan } \\
\text { lahe u donya } \\
\text { Ayah dan Bunda } \\
\text { seunang that } \\
\text { hate } \\
\text { Karna ka lahe si } \\
\text { bijeh mata }\end{array}$ & $\begin{array}{l}\text { Padatanggal } \\
3 \\
\text { novembertah } \\
\text { un } 88 \\
\text { Kamulahirke } \\
\text { dunia } \\
\text { Ayah dan } \\
\text { ibusangatbah } \\
\text { agia } \\
\text { Karenakamu } \\
\text { sudahlahirke } \\
\text { dunia }\end{array}$ \\
\hline 9. & $\begin{array}{l}\text { Tron tajak } \\
\text { manoe } \\
\text { Dara baro tron } \\
\text { tajak manoe } \\
\text { Oh lheuh manoe } \\
\text { lakee sunalein }\end{array}$ & $\begin{array}{l}\text { Turun kita } \\
\text { mandi } \\
\text { Mempelai } \\
\text { puti turunlah } \\
\text { Kita pergi } \\
\text { mandi }\end{array}$ \\
\hline
\end{tabular}

\begin{tabular}{|c|c|c|}
\hline & $\begin{array}{l}\text { Ija nyang laen } \\
\text { seunalen manoe }\end{array}$ & $\begin{array}{l}\text { Sesudah } \\
\text { mandi } \\
\text { Minta } \\
\text { salinan kain } \\
\text { yang lain } \\
\text { salinan } \\
\text { mandi }\end{array}$ \\
\hline 10. & $\begin{array}{l}\text { Hudep beu jroh } \\
\text { hai bungong } \\
\text { keumang } \\
\text { Peutimang } \\
\text { Nanggroe } \\
\text { rakyat beu } \\
\text { seunang } \\
\text { Beu jeut gata } \\
\text { keu panyoet } \\
\text { tanglong } \\
\text { Peu puengeuh } \\
\text { gampong } \\
\text { jampang tan } \\
\text { suwa }\end{array}$ & $\begin{array}{l}\text { Hidupberbah } \\
\text { agiawahaian } \\
\text { akkusayang } \\
\text { Menjagadaer } \\
\text { ah agar } \\
\text { rakyatsenang } \\
\text { Agar } \\
\text { kamumenjad } \\
\text { ipenerang } \\
\text { Agar } \\
\text { terandaerahk } \\
\text { amu }\end{array}$ \\
\hline 11. & $\begin{array}{l}\text { Tron tajak } \\
\text { manoe } \\
\text { Dara baro tron } \\
\text { tajak manoe } \\
\text { Oh lheuh manoe } \\
\text { lakee sunalein } \\
\text { Ija nyang laen } \\
\text { seunalen manoe }\end{array}$ & $\begin{array}{l}\text { Turun kita } \\
\text { mandi } \\
\text { Mempelai } \\
\text { puti turunlah } \\
\text { Kita pergi } \\
\text { mandi } \\
\text { Sesudah } \\
\text { mandi } \\
\text { Minta } \\
\text { salinan kain } \\
\text { yang lain } \\
\text { salinan } \\
\text { mandi }\end{array}$ \\
\hline 12. & Bak gata sidroe & Padadirimuk \\
\hline
\end{tabular}




\begin{tabular}{|c|c|c|}
\hline & 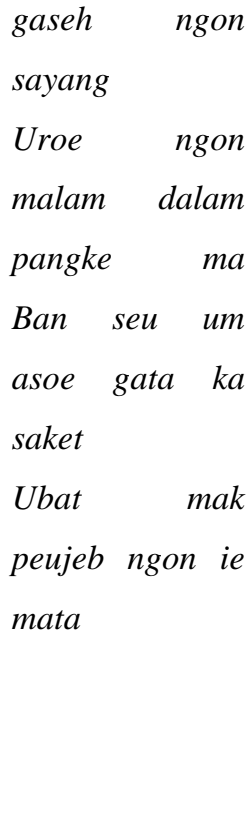 & $\begin{array}{l}\text { asihdan } \\
\text { saying } \\
\text { Siang } \\
\text { danmalamda } \\
\text { lampelukan } \\
\text { mama } \\
\text { Ketikapanas } \\
\text { kamudalamk } \\
\text { esakitan } \\
\text { Mama } \\
\text { memberikan } \\
\text { obatdengant } \\
\text { etesan air } \\
\text { mata }\end{array}$ \\
\hline 13 & $\begin{array}{l}\text { Tron tajak } \\
\text { manoe } \\
\text { Dara baro tron } \\
\text { tajak manoe } \\
\text { Oh lheuh manoe } \\
\text { lakee sunalein } \\
\text { Ija nyang laen } \\
\text { seunalen manoe }\end{array}$ & $\begin{array}{l}\text { Turun kita } \\
\text { mandi } \\
\text { Mempelai } \\
\text { puti turunlah } \\
\text { Kita pergi } \\
\text { mandi } \\
\text { Sesudah } \\
\text { mandi } \\
\text { Minta } \\
\text { salinan kain } \\
\text { yang lain } \\
\text { salinan } \\
\text { mandi }\end{array}$ \\
\hline 14. & $\begin{array}{l}\text { Bak gata } \text { sidroe } \\
\text { gaseh ngon } \\
\text { sayang } \\
\text { Dak jeut bek } \\
\text { leukang barang } \\
\text { kajan masa } \\
\text { Dak jeut bek } \\
\text { jarak meu } \\
\text { sipade }\end{array}$ & $\begin{array}{l}\text { Padadirimuk } \\
\text { asihdansaya } \\
\text { ng } \\
\text { Kalaubisajag } \\
\text { anterpisahsa } \\
\text { mpaikapan } \\
\text { pun } \\
\text { Kalaubisajan } \\
\text { gansampai }\end{array}$ \\
\hline
\end{tabular}

\begin{tabular}{|c|c|c|}
\hline & $\begin{array}{l}\text { Dak jeut bek } \\
\text { meucre meu si } \\
\text { deupa }\end{array}$ & $\begin{array}{l}\text { adajarakwala } \\
\text { upunsekecil } \\
\text { apapun } \\
\text { Kalaubisajan } \\
\text { gansampaibe } \\
\text { rpisah }\end{array}$ \\
\hline 15 & $\begin{array}{l}\text { Tron tajak } \\
\text { manoe } \\
\text { Dara baro tron } \\
\text { tajak manoe } \\
\text { Oh lheuh manoe } \\
\text { lakee sunalein } \\
\text { Ija nyang laen } \\
\text { seunalen manoe }\end{array}$ & $\begin{array}{l}\text { Turun kita } \\
\text { mandi } \\
\text { Mempelai } \\
\text { puti turunlah } \\
\text { Kita pergi } \\
\text { mandi } \\
\text { Sesudah } \\
\text { mandi } \\
\text { Minta } \\
\text { salinan kain } \\
\text { yang lain } \\
\text { salinan } \\
\text { mandi }\end{array}$ \\
\hline 16. & $\begin{array}{l}\text { Wahe putroe } \\
\text { aneuk } \\
\text { meutuwah } \\
\text { Gata lon seurah } \\
\text { meunyoe tinggai } \\
\text { poma } \\
\text { Meunyoe tajak } \\
\text { bek tuwo kamoe } \\
\text { Trep-trep sigoe } \\
\text { tajingeuk poma }\end{array}$ & $\begin{array}{l}\text { Wahaianak } \\
\text { yang baik } \\
\text { Kamusayabe } \\
\text { rikanizinmen } \\
\text { inggalkanibu } \\
\text { Andaikanper } \\
\text { gijanganlupa } \\
\text { kan kami } \\
\text { Menjenguk } \\
\text { orang } \\
\text { tuasekali- } \\
\text { sekalipulang }\end{array}$ \\
\hline 17. & $\begin{array}{l}\text { Tron tajak } \\
\text { manoe } \\
\text { Dara baro tron } \\
\text { tajak manoe } \\
\text { Oh lheuh manoe }\end{array}$ & $\begin{array}{l}\text { Turun kita } \\
\text { mandi } \\
\text { Mempelai } \\
\text { putri } \\
\text { turunlah }\end{array}$ \\
\hline
\end{tabular}




\begin{tabular}{|l|l|ll|}
\hline & lakee sunalein & Kita pergi \\
Ija nyang laen & mandi \\
& seunalen manoe & Sesudah \\
& & mandi \\
& & Minta & \\
& & salinan & kain \\
& & yang lain \\
& & salinan & \\
& & mandi & \\
\hline 18. & Wahe aneuk si & Wahaianakk \\
& biran tulang & usatu- \\
\hline
\end{tabular}

\section{Tata Busana}

Tata busanamerupakanbagian yang paling

pentingdalamsebuahpertunjukanataut arian.Padakonseppakaiantarisangatla h di perhitungkanbaikbahan, disain, warnadancarapemakaian.

DidalamtariManoePucokinipenarime nggunakanbusana adat Aceh, banyakragamwarnabajutradisiacehdi antaranya( merah, kuning, hijau, hitam, danmerahmuda),

Celanahitam, kainsongket, selempangsungket,

talipinggangsungket, kerudung, sanggulkepaladankerudungberwrnahi tam. Salah satubaju yang

\begin{tabular}{|l|lr|l|}
\hline Aneuk & lon & satunya \\
sayang si bijeh & Anakkusaya \\
mata & & gsemataway \\
Meunyoe ra & ang \\
tajak bek tuwo u & Kalausudahp \\
likeut & ergijanganlu \\
Hate & beu & pa yang di \\
meusangkot & keu & belakang \\
Blangpidie ratiselaluin & Hatid \\
& gatkeBlangp \\
\hline
\end{tabular}

digunakanadalahwarnahijaudengandi sainbordirwarnakuning di leher, dada, bawahbahu, pergelangantangandandibelakangbaw ahleher.

\section{Tata rias}

Riasmerupakanunsur yang dapatmenunjangsebuahtarianmenjadi kuat.Tatarias (make up) bukanhanyasekedarmenjadikanseora ngpenarimenjadicantik dantampan, tetapitatariasjugamembantumewujud kanekspresipenari, sesuaiperan yang dibawakannya. 


\section{Struktur Internal (Struktur Dalam)}

Struktur internal (struktur dalam) yang disebut dengan isi dan makna. Isi dari tari Manoe Pucok merupakan kesedihan seorang ibu yang akan di tinggal anaknya untuk melangkah menuju kehidupan baru berumah tangga, sedangkan Makna tari Manoe Pucok bahwa kasih sayang seorang ibu sepanjang masa, tidak akan pernah habis walaupun anaknya akan meninggalkannya untuk membangun keluarga baru bersama pasangan hidupnya. Ia bersedih bukan karena anaknya meninggalkannya, tetapi ia bersedih karena tugasnya sebagai ibu telah ada yang menggantikan, yaitu suami anaknya. Walaupun ia tahu bahwa ia akan bisa melihat anaknya dan mengurus anaknya sebagaimana biasanya. Tetapi ia ingat, bahwa sekarang sudah ada yg meringankan tanggung jawabnya sebagai seorang ibu.

\section{PENUTUP}

Sehubungandenganhasilpen elitian yang telahdilakukanmengenaibentuktari $M$ anoe

PucokpadamasyarakatBlangpidie Aceh Barat Darat, dapatdiperolehkesimpulansebagaiber ikut

\section{Kesimpulan}

1. Tari Manoe Pucok adalah tari tradisional Aceh khususnya Blagpidie Aceh Barat Daya yang telah lama dikembangkan di daerah BlangPidie Aceh Barat Daya tersebut.SejarahtariManoePucokyang diambildariceritalegendaMalelang-

Madion yang merupakankisahdaritariPho, yang dulunyamerupakantarian yang timbuldarikejadianmatinyaMalelang Madionpadasaatmenjalankanhukuma nmati, sang ibusangatkehilangankeduaanaknyase hinggaiameratapikepergiananaknyad enganberpantunataubersyairsambilm elingkarijenazahkeduaanaknya, tapi adanya perkembangan zaman, ketika 
masuknya agama islam di Aceh Barat Daya, ratapan itu tidak lagi ada, tetapi sejarah Malelang Madion tetap melekat di hati masyarakat, dengan penyajian yang berbeda, yaitu di lakukan pada saat Manoe Pucok (mandi pengantin.

\section{Tari Manoe Pucok} merupakan tarian yang diadakan dalam upacara pernikahan sebelum dilakukaannya ijab kabul. Yang isinya kesedihan orang tua melepas masa lajang anaknya unty menempuh hidup baru rumah tangga. Ragam gerak yang ada adalah : Gerak shalawat, gerak tron tajak manoe, gerak mengambil air, gerak menyiram kepala, gerak keramas rambut, dan gerak menyiram seluruh badan. Pola lantai pada tarian manoe pucok ini sangat lah sederhana dengan berentuk awal dua baris, lingkaran, segitiga, lingkaran, dua baris, lingkaran, berbentuk $\mathrm{v}$, lingkaran, dua banjar, lingkaran, segitiga, lingkaran, setengah lingkaran, segitiga dan yang terakhir lingkaran, yang di tarikan oleh penari-penari wanita yng berjumlah 8 orang. Pola lantai pada tarian Manoe
Pucok ini sangatlah sederhana dengan berbentuk awal dua baris, lingkaran, segitiga, lingkaran, berbentuk kerucut, dua banjar dan setengah lingkaran. Makna tari Manoe pucok dalam upacara perkawinan adalah ungkapan kesediahan orang tua melepas kepergian anaknya untuk menempuh hidup berumah tangga.

\section{Saran}

Berdasarkanbeberapakesimpulan di atas, terhadapbentuktariManoePucokpada masyarakatBlangpidie Aceh Barat Dayamakapenulismemberikanbebera pa saran berikut:

1. Setelah dilakukannya penelitian ini, penulis berharap agar pemerintah selalu memberikan perhatian terhadap kesenian, baik itu pemerintah yang ada di Aceh Barat Daya khususnya Blangpidie

2. Kepada para seniman, baik di Kota Blangpidie maupun di Kabupaten Aceh Barat Daya agar selalu berkarya, memperhatikan dan memberikan pengarahan serta pengenalan kepada masyarakat untuk tetap melestarikan budaya. 
3. Pada generasi muda, khususnya pemuda Aceh disarankan untuk mengetahui tentang Tari Manoe Pucok, sehingga tarian ini akan tetap hidup dan terjaga kelestariannya.
DAFTAR PUSTAKA

abdul

Chaer.2003.

"LinguistikUmum".Jakarta : PT RinekaCipta

AstiniSiluh Made, UtinaUsrekTani 2007 ,

TariPendetSebagaiTariBalih

Balihan, HarmoniaVol VIII,

Semarang.

Aziz, AlimutHidayat, 2007, MetodePenelitianKebudayaa ndanTeknikAnalisisData,Sura baya :Salemba Media.

Budiono, 2005 , BentukDalamKarya,Bandung :Pustaka

Cristin, Nova, Adelina s, "KarakteristikLandekPadaM asyarakatKaro. ”SkripsiSeniT ari, Sendratasik

FakultasBahasadanSeni.

Dedi, Suherman, "BentukPenyajianTariHasyim MeulangkahDalamUpacara ManoePucokPadaSunatRosul Di

DesaSeunalupKecamatanMa nggeng Aceh Barat Daya". Skripsi.UniversitasSyah Kuala.

Danesi, Marcel (2012). Pesan, Tanda, danMakna. Yogyakarta: Jalasutra. 
Dillistone,

F.W.

2002.DayakekuatanSimbol

(The Power of

Symbols),PustakaFilsafat,

PenerbitKanisius, Yogyakarta

Djelantik,

wujudNyataDalamTari,

Semarang :Pustaka

Fitri, Fitriani,"BentukPenyajianTari Pho Di Gampong Ujung Padang

KecamatanSusohKabupaten

Aceh Barat Daya".

Skripsi.UniversitasSyah

Kuala.

Hadi, Sumandiyo, 1984, AspekAspekDasarKoreografiKelom pok, Yogyakarta : ELKAPHI

Kamirsa.1997.

KamusLengkapBahasa

Indonesia.PenerbitKartika

Surabaya

Koentjaraningrat,

1987.MetodePenelitianMasya rakat.Jakarta :Gramedia.

Maghfira, $\quad$ Fitri, 2011 "BentukPenyajianTariInekMa yak Pukes PadaMasyarakatGayo Aceh Tengah. 'SkripsiSeniTari, Sendratasik.

FakultasBahasadanSeni, UniversitasNegeri Medan.

Murgianto, Sal, 1983, Koreografi PengetahuanDasarKomposisi
Tari, Jakarta

(DirektoratJendral)

PendidikamDasardanMeneng

ahDepartemanPendidikan

Dan Kebudayaan.

Nurwani

2014.

"BahanAjarPengetahuanSeni

Tari”,Medan: Unimed Press.

Peterson, Anya, 2007. The AntropologiOf Dance,

Terjemahan F.X Widaryanto. Bandung : STSI Press

Prihatini Sri Nanik 2008, SeniPertunjukan Rakyat

Kedu, Surakarta :Pascasarjanadan ISI Press Surakarta.

Roy, Anya Peterson, 2007. AntropologiTari.Terjemahan F.X Widaryanto. Bandung: STSI Pres Bandung

Soedarsono. 1972. Djawa Dan Bali. Yogyakarta: Gajah Mada University Press

Tilar. 2002. PendidikanKebudayaan Dan

MasyarakatMadaniIndonesi.

Bandung :Rosdakarya

Wahyu, DesianaSyahzuar, 2009.

"TariKesumeGayoPadaMasy arakatGayoKabupaten Aceh Tenggara

TinjauanTerhadapBentuk. "S 
Gesture

kripsiSeniTari, Sendratasik.

UniversitasNegeriMedan

FakultasBahasadanSeni, 